\title{
Genetic factors affect the etiology, clinical characteristics and outcome of autoimmune hepatitis
}

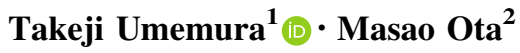

Received: 29 October 2015/Accepted: 19 November 2015/Published online: 10 December 2015

(C) Japanese Society of Gastroenterology 2015

\begin{abstract}
Autoimmune hepatitis (AIH) is characterized by chronic inflammation of the liver, hypergammaglobulinemia, the presence of serum autoantibodies, histologic evidence of interface hepatitis, and a favorable response to immunosuppressive treatment. Although the etiology of AIH remains undefined, human leukocyte antigen (HLA) class II alleles have been associated with disease onset for decades. AIH resistance and severity are presumably linked to HLA alleles as well. Individuals in different geographic regions of the world may have varying susceptibility alleles that reflect indigenous triggering antigens. In this review, we describe the influence of HLA alleles and gene polymorphisms on AIH, along with the results of genome-wide association studies on this disease.
\end{abstract}

Keywords HLA - Autoimmune hepatitis - Primary biliary cirrhosis

\section{Introduction}

Autoimmune hepatitis (AIH) is characterized by chronic inflammation of the liver, hypergammaglobulinemia, the presence of serum autoantibodies, histologic evidence of interface hepatitis, and a favorable response to immunosuppressive treatment [1-3]. Two types of AIH have been

Takeji Umemura

tumemura@shinshu-u.ac.jp

1 Division of Gastroenterology and Hepatology, Department of Medicine, Shinshu University School of Medicine, 3-1-1 Asahi, Matsumoto 390-8621, Japan

2 Department of Legal Medicine, Shinshu University School of Medicine, 3-1-1 Asahi, Matsumoto 390-8621, Japan identified to date based on serum autoantibody profiles: type 1 (AIH-1), which is positive for anti-nuclear and/or anti-smooth muscle antibodies, and type 2 (AIH-2), defined by positivity for anti-liver kidney microsomal type 1 or anti-liver cytosol type 1 antibodies. Although the etiology of AIH is unknown, it is believed to be a multifactorial polygenic disease presumably caused by interactions among trigger and environmental factors in genetically susceptible individuals.

\section{Human leukocyte antigen}

Located in the major histocompatibility complex (MHC), the human leukocyte antigen (HLA) loci are the most genetically diverse in the human genome. The HLA genomic sequence was one of the first large regions to be fully deciphered [4], and has been found to contain approximately 260 genes over a span of roughly $4 \mathrm{Mb}$ on chromosomal region $6 \mathrm{p} 21.3$ (Fig. 1). The highly polymorphic genes that encode the classical HLA class I and II alloantigens play important roles in the specificity determination of adaptive immune responses, susceptibility to autoimmune and infectious diseases, and transplantation outcome.

The IMGT/HLA database provides an online locusspecific database (LSDB) of the allelic sequences of HLA genes and nomenclature for the analysis of HLA systems. HLA antigen/allele designations are described in a recommended and standardized convention (http://hla.alleles. org), which starts with the HLA prefix denoting the HLA region, followed by a hyphen to separate the particular HLA locus from the HLA prefix. An asterisk (such as in $H L A-A^{*}$ and $H L A-D R B I^{*}$ ) is a separator for the next set of digits. The ensuing one or more two-digit numbers are separated by colons (i.e., field separators). The first set of 
Fig. 1 Location of HLA genes and the number of HLA alleles
Location of the HLA Genes and Number of HLA alleles

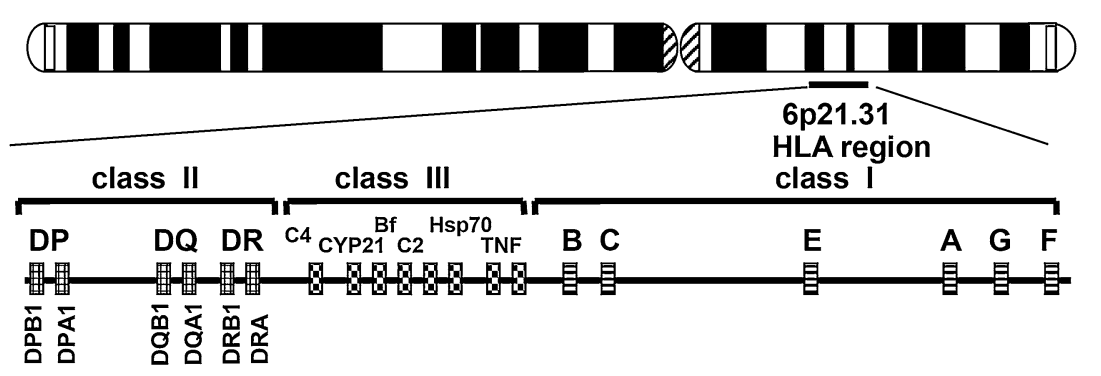

\begin{tabular}{llll}
\hline Number of HLA alleles (2015) & \multicolumn{3}{c}{ HLA Database http://www.ebi.ac.uk/imgt/hla/ } \\
\hline HLA-A & \multicolumn{4}{c}{ HLA-DR } \\
$\begin{array}{l}\text { Serological type: } \\
\text { DNA type: }\end{array}$ & 25 & Serological type: & 18 \\
& 3,107 & DNA type: DRA & 7 \\
HLA-B & & DRB & 1,726 \\
Serological type: & 50 & HL-DQ & 7 \\
DNA type: & 3,887 & Serological type: & 71 \\
& & DNA type: DRA & 51 \\
HLA-C & & DRB & 459 \\
Serological type: & 9 & HLA-DP & \\
DNA type: & 2,623 & Derological type: & 6 \\
& & DNA type: DRA & 37 \\
& & DRB & 193 \\
\hline
\end{tabular}

digits describes the allele family that corresponds to the serological antigen carried by the allotype (field 1). The second set of digits specifies one or more nucleotide substitutions that change the amino acid sequence of the encoded protein (i.e., non-synonymous substitution; field 2). The third set of digits distinguishes alleles that denote any synonymous mutations within the coding frame of the gene (field 3). The mutations outside the coding region, such as introns or $5^{\prime}$ or $3^{\prime}$ untranslated regions, are distinguished by the use of a fourth set of digits (field 4). A suffix may also be added to specify expression level or other nongenomic data by indicating 'A' ('Aberrant' expression), 'C' (present in the 'Cytoplasm' but not on the cell surface), 'L' ('Low' cell surface expression), 'N' ('Null' allele), 'Q' ('Questionable' expression), or 'S' (expressed as a soluble 'Secreted' molecule but not present on the cell surface).

HLA typing was initially carried out by serological analysis. However, following the introduction and evolution of the polymerase chain reaction (PCR), many variations of HLA typing methods, such as PCR-restriction fragment length polymorphism (PCR-RFLP), PCR-singlestrand conformation polymorphism (PCR-SSCP), PCR-sequence-specific oligonucleotides (PCR-SSO), and PCRsequence-specific primers and sequence-based typing (PCR-SBT), have emerged. As most of the polymorphic sequence motif loci are localized in the second and third exons of HLA class I and in the second exon of HLA class II, the minimum requirements for HLA-DNA typing are complete sequencing of these areas of interest. The two methods that are currently predominant in HLA-DNA typing are PCR-SSO, such as the Luminex commercial methodology, and PCR-SBT by the Sanger method using a capillary auto-sequencing device. These methods capture parts of sequence information in exons 2 and 3. Recently, high-throughput genotyping of HLA genes has been established using next-generation sequencing (NGS) techniques [5] that can determine HLA allele sequences derived from a single DNA molecule with a high level of parallelism. HLA-DNA typing using the NGS platform provides numerous benefits, including high-resolution genotyping at the 4-field level, a reduction in phase ambiguity, highthroughput typing using barcodes, detection of null alleles, and cost effectiveness compared with conventional methods. High-throughput genotyping of HLA genes in patients with autoimmune diseases is presently underway (Fig. 2).

\section{Associations between HLA and AIH susceptibility}

A genetic predisposition to $\mathrm{AIH}$ has been attributed to several MHC genes, especially those that code for HLAs. HLA serology was studied extensively in AIH patients 
Fig. 2 Definitions of HLA nomenclature and typing resolution

\section{Definitions of HLA nomenclature and typing resolution}

http://hla.alleles.org/nomenclature/naming.html

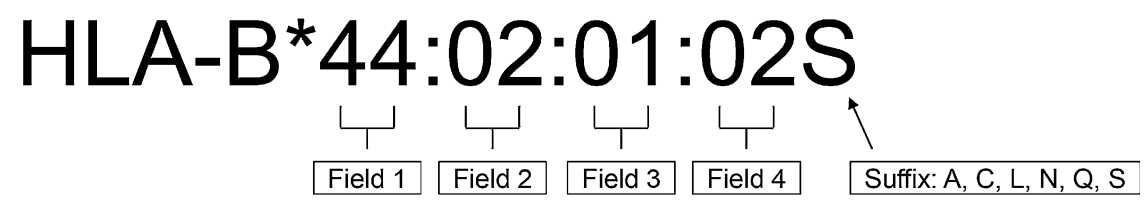

A: Aberrant, C: Cytoplasm, L: Low, N: Null, Q: Questionable, S: Secreted

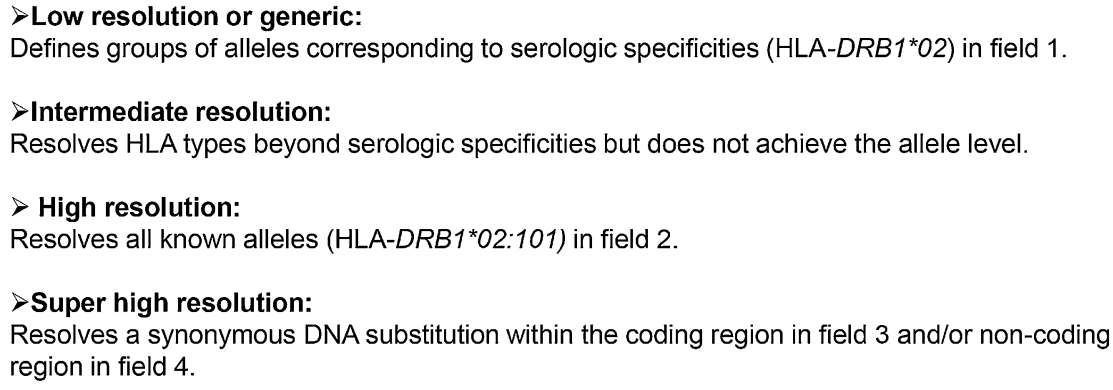

from 1980 through the early 1990s (Table 1). In northern European populations, the A1-D8-DR3 haplotype was associated with susceptibility to AIH [6-8]. By excluding the DR3 antigen, DR4 was found to be a secondary antigen related to the disease [8] and was linked to AIH onset in Japan [9]. Since DR3 is scarce in the Japanese general population, the susceptibility genes for AIH are presumably different from those in white populations.

Following the advent of HLA typing by PCR methods, a number of studies were published on culpable HLA alleles. In Mexican [10], Japanese [11, 12], and Korean [13] populations, AIH was associated with the $D R B 1 * 04: 04$ and $D R B$ 1:04:05 alleles. In European populations, a link was reported between $\mathrm{AIH}$ and the $D R B 1^{* 03: 01}$ and $D R B 1^{*} 04: 01$ alleles $[14,15]$. In Latin Americans, $D R B 1 * 13: 01$ was apparently correlated with AIH susceptibility [16-19]. Several investigations have also described protective alleles for AIH. For instance, $D R B 1 * 15: 01$ was related to prevention of disease onset in Japanese and North American cohorts $[12,15]$. Since the relative linkage disequilibrium value for HLA alleles is very high within populations, haplotype analysis is also important in the evaluation of HLA susceptibility and protection. In Japan $[11,12]$ and Korea [13], the HLA-DRBI*04:05$D Q B 1 * 04: 01$ haplotype was associated with susceptibility to AIH (Table 2), while DRB1*15:01-DQB1*06:02 conferred resistance to AIH in the Japanese [12]. $D R B 1 * 13: 01-D Q B 1 * 06: 03$ was found to be a risk haplotype in Latin America. In northern Europe and North America, three primary haplotypes have been associated with the disease: the frequency of the $D R B 1 * 03: 01$ $D Q B 1 * 02: 01$ and $D R B 1 * 04: 01-D Q B 1 * 03: 02$ haplotypes was significantly increased and that of $D R B 1 * 15: 01$ $D Q A 1 * 01: 02-D Q B 1 * 06: 02$ was significantly decreased in patients with AIH compared with disease-free individuals [15]. However, the mechanisms of an HLA association with autoimmune disease are not clearly elucidated and are largely hypothetical. The most probable model is a breakdown in immunological tolerance to self-antigens presented by aberrant disease-associated HLA molecules. The properties of the peptide-binding groove of HLA molecules determine the targeting of particular autoantigens. As the amino acids that form the binding pockets are highly polymorphic, binding specificity can vary considerably among specific HLA alleles. The DRBI association with type 1 AIH may be explained by the amino acid motifs in the corresponding antigen-presenting grooves. In European and North American patients with AIH of this type, a model based on lysine at position 71 of the DR $\beta$ polypeptide has been proposed [20], and earlier studies also implicated a histidine residue at position 13 of the DR $\beta$ polypeptide as a critical determinant of disease susceptibility in Japan [21]. In a larger Japanese cohort, the incidence of valine- 11 , histidine-13, and serine- 57 encoded by $D R B 1 * 04: 05$ was significantly higher in AIH patients than in normal controls [12]. Moreover, a valine/glycine dimorphism at position 86 of the DR $\beta$ polypeptide has been suggested in patients from Argentina and Brazil. The above studies indicate that multiple genetic associations with AIH exist among different populations. 
Table 1 HLA association studies in AIH

\begin{tabular}{|c|c|c|c|c|c|c|c|}
\hline Year & Country & HLA studied & $\begin{array}{l}\text { Significant HLA } \\
\text { association }\end{array}$ & $\mathrm{AIH}$ & Controls & $P$ & References \\
\hline 1980 & Australia & $\mathrm{A}, \mathrm{B}, \mathrm{DRw}$ & DRw3 & $74 \%$ & $32 \%$ & & Mackay \\
\hline 1987 & USA & $\mathrm{A}, \mathrm{B}, \mathrm{DR}$ & B8-DR3 & $60 \%(6 / 10)$ & $39 \%(20 / 51)$ & & Krawitt \\
\hline \multirow[t]{2}{*}{1990} & Japan & A, B, DR, DQ & Bw54 & $45.2 \%(14 / 31)$ & $10.9 \%(42 / 386)$ & & Seki \\
\hline & & & DR4 & $90.3 \%(28 / 31)$ & $\begin{array}{l}38.6 \%(149 / \\
386)\end{array}$ & & \\
\hline \multirow[t]{2}{*}{1991} & UK & $\mathrm{A}, \mathrm{B}, \mathrm{DR}$ & A1-B8-DR3 & $38 \%(42 / 110)$ & $11 \%(11 / 100)$ & $<0.0005$ & Donaldson \\
\hline & & & DR4 & $80 \%(35 / 44)$ & $39 \%(31 / 79)$ & $0.0013(\mathrm{Pc})$ & \\
\hline \multirow[t]{3}{*}{1992} & Japan & DR, DQA1, DQB1, DPB1 & DRB $1 * 0405$ & $67.3 \%(33 / 49)$ & $29.6 \%(13 / 44)$ & $<0.005(\mathrm{Pc})$ & Seki \\
\hline & & & DQA1*0301 & $91.8 \%(45 / 49)$ & $63.6 \%(28 / 44)$ & $<0.05(\mathrm{Pc})$ & \\
\hline & & & DQB1*0401 & $65.3 \%(32 / 49)$ & $27.3 \%(12 / 44)$ & $<0.001(\mathrm{Pc})$ & \\
\hline 1993 & UK & A, B, DR, DQ, DPB1 & $\begin{array}{l}\text { A1-B8-DR3-DQ2- } \\
\text { DPB1*0401 }\end{array}$ & $27 \%(27 / 101)$ & $7 \%(7 / 105)$ & $<0.0005$ & Manabe \\
\hline \multirow[t]{2}{*}{1994} & UK & DRB, DQA, DQB & DRB3*0101 & $58 \%(69 / 119)$ & $25 \%(44 / 177)$ & $<0.000001(\mathrm{Pc})$ & Doherty \\
\hline & & & DRB1*04:01 & $81 \%$ & $42 \%$ & & \\
\hline \multirow[t]{2}{*}{1994} & Argentina & DRB1, DQB1 & DRB1*1301 & $66.6 \%$ & $10.5 \%$ & $0.00001(\mathrm{Pc})$ & Fainboim \\
\hline & & & DQB1*0603 & & & 0.00001 & \\
\hline \multirow[t]{6}{*}{1997} & USA & A, B, DRB1, DQA1, & DRB $1 * 0301$ & $51 \%(44 / 86)$ & $19 \%(19 / 102)$ & $0.00003(\mathrm{Pc})$ & Strettell \\
\hline & & & DQA1*0501 & $56 \%(48 / 86)$ & $34 \%(35 / 102)$ & $0.0341(\mathrm{Pc})$ & \\
\hline & & & DQB1*0201 & $58 \%(50 / 86)$ & $30 \%(31 / 102)$ & $0.00143(\mathrm{Pc})$ & \\
\hline & & & DRB $1 * 0401$ & $55 \%(23 / 42)$ & $17 \%(14 / 83)$ & $0.000132(\mathrm{Pc})$ & \\
\hline & & & DRB1*1501 & $12 \%(10 / 86)$ & $30 \%(31 / 120)$ & $0.021(\mathrm{Pc})$ & \\
\hline & & & DQA1*0102 & $17 \%(15 / 86)$ & $38 \%(39 / 102)$ & $0.0187(\mathrm{Pc})$ & \\
\hline 1997 & UK & $\mathrm{C}$ & $\mathrm{Cw}^{*} 0701$ & $54 \%(47 / 87)$ & $34 \%(34 / 100)$ & 0.024 & Strettell \\
\hline \multirow[t]{4}{*}{1999} & Brazil & DRB, DQB1 & $\mathrm{DRB} 1 * 13$ & $70 \%(78 / 111)$ & $26 \%(33 / 129)$ & $<0.00001$ & Bittencourt \\
\hline & & & DRB3 & $93 \%(103 /$ & $69 \%(89 / 129)$ & 0.00007 & \\
\hline & & & DQB1*06 & 111) & $41 \%(53 / 129)$ & 0.00007 & \\
\hline & & & & $68 \%(75 / 111)$ & & & \\
\hline 1999 & Argentina & DRB1, DRB3, DQA1, DQB1 & DRB $1 * 0405$ & $11 \%(9 / 84)$ & $1 \%(2 / 208)$ & $<0.005$ (Pc) & Pando \\
\hline 2001 & Brazil & DRB1, DR3, DQA1, DAB1 & DRB $1 * 1301$ & $87 \%(34 / 39)$ & $50 \%(11 / 22)$ & 0.00247 & Goldberg \\
\hline 2003 & China & $\mathrm{DRB} 1$ & DRB $1 * 04$ & $22 \%(7 / 32)$ & $6 \%(3 / 48)$ & $0.08(\mathrm{Pc})$ & Qiu \\
\hline \multirow[t]{2}{*}{2007} & Venezuela & $\mathrm{A}, \mathrm{B}, \mathrm{C}, \mathrm{DR}, \mathrm{DQ}$ & DRB $1 * 1301$ & $34 \%(14 / 41)$ & $7 \%(8 / 111)$ & $0.003(\mathrm{Pc})$ & Fortes \\
\hline & & & DQB1*04 & $2 \%(1 / 41)$ & $22 \%(24 / 111)$ & $0.016(\mathrm{Pc})$ & \\
\hline \multirow[t]{4}{*}{2008} & Korea & A, B, C, DRB1, DQB1 & DRB $1 * 0405$ & $37 \%(23 / 62)$ & $14 \%(21 / 154)$ & 0.0001 & Lim \\
\hline & & & DQB1*0401 & $37 \%(23 / 62)$ & $13 \%(20 / 154)$ & 0.00006 & \\
\hline & & & DRB $1 * 0406$ & $2 \%(1 / 62)$ & $12 \%(18 / 154)$ & 0.018 & \\
\hline & & & DQB1*0301 & $13 \%(8 / 62)$ & $28 \%(43 / 154)$ & 0.024 & \\
\hline \multirow[t]{6}{*}{2014} & Japan & A, B, C, DRB1, DQB1, & $A * 24: 02$ & $35 \%(108 /$ & $22 \%(90 / 402)$ & $0.0053(\mathrm{Pc})$ & Umemura \\
\hline & & DPB1 & $C * 01: 02$ & 312) & $14 \%(58 / 402)$ & $0.036(\mathrm{Pc})$ & \\
\hline & & & DRB1*04:05 & $23 \%(73 / 312)$ & $11 \%(45 / 402)$ & $4.0 \times 10^{-9}$ & \\
\hline & & & DQB1*04:01 & $30 \%(95 / 312)$ & $11 \%(45 / 402)$ & (Pc) & \\
\hline & & & DQB $1 * 06: 02$ & $30 \%(94 / 312)$ & $13 \%(53 / 402)$ & $3.7 \times 10^{-9}$ & \\
\hline & & & & $5 \%(17 / 312)$ & & $0.009(\mathrm{Pc})$ & \\
\hline
\end{tabular}

\section{Severity and clinical phenotype}

Although susceptibility and resistance to AIH are strongly influenced by HLA alleles, these alleles can also act as modifiers of clinical phenotype [12, 14]. In Japan, the HLA $D R B 1 * 04: 05-D Q B 1 * 04: 01$ susceptibility haplotype was correlated with elevated serum IgG levels and anti-smooth muscle positivity, and the $D R B 1 * 15: 01-D Q B 1 * 06: 02$ protection haplotype was associated with the development of hepatocellular carcinoma. $D R B 1 * 08: 03-D Q B 1 * 06: 01$, which is an important risk haplotype in primary biliary cirrhosis [22], was more frequent in patients who progressed to hepatic failure. In whites with $\mathrm{AIH}$, the presence of HLA-DRB ${ }^{*} 04: 01$ was associated with decreased severity, a lower frequency of relapse, and presentation at

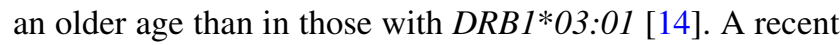


Table 2 HLA haplotypes in AIH

\begin{tabular}{|c|c|c|c|c|c|c|}
\hline Year & Country & Haplotype & $\mathrm{AIH}$ & Controls & $P$ & References \\
\hline 1994 & Argentina & DRB1*13:01-DQB1*0603 & & & 0.00001 & Fainboim \\
\hline 1997 & USA & $\begin{array}{l}\text { DRB3*0101-DRB } 1 * 0301- \\
\text { DQA } 1 * 0501-D Q B 1 * 0201 \\
\text { DRB4*0103-DRB } 1 * 0401- \\
\text { DQA } 1 * 0302-D Q B 1 * 0301 \\
\text { DRB4*0103-DRB } 1 * 0401-D Q A 1 * \\
\text { 0302-DQB } 1 * 0302 \\
\text { DRB5*0101-DRB } 1 * 1501\end{array}$ & $\begin{array}{l}48 \% \\
26 \%(\mathrm{DRB} 1 * 0301- \\
\text { negative) } \\
24 \% \\
12 \%\end{array}$ & $\begin{array}{l}19 \% \\
10 \% \\
5 \% \\
29 \%\end{array}$ & $\begin{array}{l}0.000021 \\
0.03 \\
0.05 \\
0.021\end{array}$ & Strettell \\
\hline 2008 & Korea & DRB $1 * 0405-\mathrm{DQB} 1 * 0401$ & $37 \%(23 / 62)$ & $12 \%(19 / 154)$ & $<0.0001$ & Lim \\
\hline 2014 & Japan & $\begin{array}{l}\text { DRB1*04:05-DQB } 1 * 04: 01 \\
\text { DRB1*15:01-DQB1*06:02 }\end{array}$ & $\begin{array}{l}30 \%(94 / 312) \\
5 \%(17 / 312)\end{array}$ & $\begin{array}{l}11 \%(44 / 402) \\
13 \%(53 / 402)\end{array}$ & $\begin{array}{l}1.2 \times 10^{-10} \\
0.00057\end{array}$ & Umemura \\
\hline
\end{tabular}

study from the Netherlands also revealed that HLA$D R B 1 * 03: 01 / \mathrm{HLA}-D R B 1 * 04: 01$-positive patients had higher International Autoimmune Hepatitis Group (IAIHG) scores than did HLA-DRB1*03:01/DRB1*04:01-negative patients [23]. While HLA-DRBI*03:01 was associated with higher IgG levels, DRBI*04:01 was linked to older presentation age and a female preponderance. Furthermore, $D R B 1 * 03: 01$-positive patients were more likely to receive immunosuppressive medication and liver transplantation.

The role of HLA in type 2 AIH is not well studied due to low disease prevalence, although published data have suggested associations with HLA-DRBI*07 and HLA$D Q B 1 * 02: 01[17,24]$.

\section{Serologic phenotype}

Antibodies to soluble liver antigen/liver pancreas (antiSLA/LP) characterize patients with severe inflammatory activity and a propensity for relapse after corticosteroid withdrawal [25-28]. As they have been associated with $D R B 1 * 03: 01[26,27]$, antibodies to SLA/LP may also reflect pathogenic mechanisms prompted by $D R B 1 * 03: 01$ or other genetic factors working in epistasis with this principal genetic driver. In Japan, none of 100 patients with type 1 AIH were positive for anti-SLA/LP (Umemura, unpublished data). Since $D R B 1 * 03: 01$ is not commonly found in the Japanese, however, this AIH phenotype might be present only in European and American populations.

\section{Non-HLA associations in AIH}

Although antigen presentation is a critical step in the immune response, numerous other stages exist that may be modulated by host genetic variation, such as the immediate aftermath of MHC-peptide-T-cell receptor interactions, at which time signaling by accessory molecules determines the ensuing course of events. One such accessory molecule, cytotoxic lymphocyte antigen 4 $(C T L A-4)$, is of particular interest. Switching from immune activation to immune memory occurs through the upregulation of CTLA-4 on CD25+ T cells. In North American and northern European patients, a polymorphism of the CTLA-4 gene $(+49 \mathrm{~A} / \mathrm{G})$ was associated with increased incidence of AIH [29, 30]. However, this relationship has not been confirmed in studies from Japan or elsewhere [31-35].

Polymorphisms of the human Fas gene [tumor necrosis factor-receptor superfamily (TNFRSF) gene] have been associated with AIH onset in Japan [36]. In Caucasoid patients, an adenosine-to-guanine single-nucleotide polymorphism in the Fas gene (TNFRSF6) was related to the early development of cirrhosis [37] as well.

A polymorphism in tumor necrosis factor $\alpha(T N F A * 2)$ has been linked to highly inducible and elevated constitutive levels of TNF- $\alpha$ in the serum [38], and was shown to be more frequent in young white AIH patients who responded less favorably to corticosteroid therapy than patients without the polymorphism [39, 40]. Meanwhile, a case-control association study of 400 polymorphic microsatellite markers identified associations with chromosome 11 and 18 in the Japanese [41].

Finally, although genome-wide association studies have been conducted on primary biliary cirrhosis [42-45] and primary sclerosing cholangitis [46-48], no such reports on AIH appeared until 2014, when de Bore et al. performed the first multi-center genome-wide association study on type 1 AIH predisposition in Dutch and German patients [49]. The authors described significant associations with both HLA and non-HLA loci, including $S H 2 B 3$ (rs3184504, 12q24; $P=7.7 \times 10^{-8}$ ) and CARD10 (rs6000782, 22q13.1; $P=3.0 \times 10^{-6}$ ). Importantly, the strong correlation between AIH and the HLA region was 
confirmed in this analysis: HLA-DRB $1 * 03: 01(P=5.3 \times$ $\left.10^{-49}\right)$ as well as HLA-DRB1*04:01 $\left(P=2.8 \times 10^{-18}\right)$ were identified as prominent susceptibility genotypes.

\section{Conclusions and future directions}

The recent advancements in whole exome and genome sequencing have enabled the precise identification of numerous genes associated with susceptibility, resistance, disease severity, and outcome in AIH. Future genome-wide association studies are warranted both in Japan and abroad.

\section{Compliance with ethical standards}

Conflict of Interest: Takeji Umemura and Masao Ota declare that they have no conflict of interst.

Human Rights: This study does not include any data about human subjects.

Informed Consent: This study does not involve human subjects and does not apply to giving Informed Consent.

\section{References}

1. Czaja AJ, Manns MP. Advances in the diagnosis, pathogenesis, and management of autoimmune hepatitis. Gastroenterology. 2010;139(58-72):e4.

2. Manns MP, Czaja AJ, Gorham JD, Krawitt EL, Mieli-Vergani G, Vergani D, et al. Diagnosis and management of autoimmune hepatitis. Hepatology. 2010;51:2193-213.

3. Heneghan MA, Yeoman AD, Verma S, Smith AD, Longhi MS. Autoimmune hepatitis. Lancet. 2013;382:1433-44.

4. The MHC Sequencing Consortium. Complete sequence and gene map of a human major histocompatibility complex. Nature. 1999;401:921-3.

5. Shiina T, Suzuki S, Ozaki Y, Taira H, Kikkawa E, Shigenari A, et al. Super high resolution for single molecule-sequence-based typing of classical HLA loci at the 8-digit level using next generation sequencers. Tissue Antigens. 2012;80:305-16.

6. Mackay IR, Tait BD. HLA associations with autoimmune-type chronic active hepatitis: identification of B8-DRw3 haplotype by family studies. Gastroenterology. 1980;79:95-8.

7. Krawitt EL, Kilby AE, Albertini RJ, Schanfield MS, Chastenay BF, Harper PC, et al. Immunogenetic studies of autoimmune chronic active hepatitis: HLA, immunoglobulin allotypes and autoantibodies. Hepatology. 1987;7:1305-10.

8. Donaldson PT, Doherty DG, Hayllar KM, McFarlane IG, Johnson PJ, Williams R. Susceptibility to autoimmune chronic active hepatitis: human leukocyte antigens DR4 and A1-B8-DR3 are independent risk factors. Hepatology. 1991;13:701-6.

9. Seki T, Kiyosawa K, Inoko H, Ota M. Association of autoimmune hepatitis with HLA-Bw54 and DR4 in Japanese patients. Hepatology. 1990;12:1300-4.

10. Vazquez-Garcia MN, Alaez C, Olivo A, Debaz H, Perez-Luque E, Burguete A, et al. MHC class II sequences of susceptibility and protection in Mexicans with autoimmune hepatitis. J Hepatol. 1998;28:985-90.
11. Seki T, Ota M, Furuta S, Fukushima H, Kondo T, Hino K, et al. HLA class II molecules and autoimmune hepatitis susceptibility in Japanese patients. Gastroenterology. 1992;103:1041-7.

12. Umemura T, Katsuyama Y, Yoshizawa K, Kimura T, Joshita S, Komatsu M, et al. Human leukocyte antigen class II haplotypes affect clinical characteristics and progression of type 1 autoimmune hepatitis in Japan. PLoS ONE. 2014;9:e100565.

13. Lim YS, Oh HB, Choi SE, Kwon OJ, Heo YS, Lee HC, et al. Susceptibility to type 1 autoimmune hepatitis is associated with shared amino acid sequences at positions 70-74 of the HLADRB1 molecule. J Hepatol. 2008;48:133-9.

14. Doherty DG, Donaldson PT, Underhill JA, Farrant JM, Duthie A, Mieli-Vergani G, et al. Allelic sequence variation in the HLA class II genes and proteins in patients with autoimmune hepatitis. Hepatology. 1994;19:609-15.

15. Strettell MD, Donaldson PT, Thomson LJ, Santrach PJ, Moore SB, Czaja AJ, et al. Allelic basis for HLA-encoded susceptibility to type 1 autoimmune hepatitis. Gastroenterology. 1997;112: 2028-35.

16. Fainboim L, Marcos Y, Pando M, Capucchio M, Reyes GB, Galoppo C, et al. Chronic active autoimmune hepatitis in children. Strong association with a particular HLA-DR6 (DRB1*1301) haplotype. Hum Immunol. 1994;41:146-50.

17. Bittencourt PL, Goldberg AC, Cancado EL, Porta G, Carrilho FJ, Farias AQ, et al. Genetic heterogeneity in susceptibility to autoimmune hepatitis types 1 and 2. Am J Gastroenterol. 1999;94: 1906-13.

18. Goldberg AC, Bittencourt PL, Mougin B, Cancado EL, Porta G, Carrilho F, et al. Analysis of HLA haplotypes in autoimmune hepatitis type 1: identifying the major susceptibility locus. Hum Immunol. 2001;62:165-9.

19. Fortes MDP, Machado IV, Gil G, Fernandez-Mestre M, Dagher L, Leon RV, et al. Genetic contribution of major histocompatibility complex class II region to type 1 autoimmune hepatitis susceptibility in Venezuela. Liver Int. 2007;27:1409-16.

20. Donaldson PT. Genetics of liver disease: immunogenetics and disease pathogenesis. Gut. 2004;53:599-608.

21. Ota M, Seki T, Kiyosawa K, Furuta S, Hino K, Kondo T, et al. A possible association between basic amino acids of position 13 of DRB1 chains and autoimmune hepatitis. Immunogenetics. 1992;36:49-55.

22. Umemura T, Joshita S, Ichijo T, Yoshizawa K, Katsuyama Y, Tanaka E, et al. Human leukocyte antigen class II molecules confer both susceptibility and progression in Japanese patients with primary biliary cirrhosis. Hepatology. 2012;55:506-11.

23. van Gerven NM, de Boer YS, Zwiers A, Verwer BJ, Drenth JP, van Hoek B, et al. HLA-DRB1*03:01 and HLA-DRB1*04:01 modify the presentation and outcome in autoimmune hepatitis type-1. Genes Immun. 2015;16:247-52.

24. Djilali-Saiah I, Fakhfakh A, Louafi H, Caillat-Zucman S, Debray D, Alvarez F. HLA class II influences humoral autoimmunity in patients with type 2 autoimmune hepatitis. J Hepatol. 2006;45: 844-50.

25. Baeres M, Herkel J, Czaja AJ, Wies I, Kanzler S, Cancado EL, et al. Establishment of standardised SLA/LP immunoassays: specificity for autoimmune hepatitis, worldwide occurrence, and clinical characteristics. Gut. 2002;51:259-64.

26. Czaja AJ, Donaldson PT, Lohse AW. Antibodies to soluble liver antigen/liver pancreas and HLA risk factors for type 1 autoimmune hepatitis. Am J Gastroenterol. 2002;97:413-9.

27. Ma Y, Okamoto M, Thomas MG, Bogdanos DP, Lopes AR, Portmann B, et al. Antibodies to conformational epitopes of soluble liver antigen define a severe form of autoimmune liver disease. Hepatology. 2002;35:658-64. 
28. Czaja AJ, Shums Z, Norman GL. Frequency and significance of antibodies to soluble liver antigen/liver pancreas in variant autoimmune hepatitis. Autoimmunity. 2002;35:475-83.

29. Agarwal K, Czaja AJ, Jones DE, Donaldson PT. Cytotoxic T lymphocyte antigen-4 (CTLA-4) gene polymorphisms and susceptibility to type 1 autoimmune hepatitis. Hepatology. 2000;31: 49-53.

30. Djilali-Saiah I, Ouellette P, Caillat-Zucman S, Debray D, Kohn JI, Alvarez F. CTLA-4/CD 28 region polymorphisms in children from families with autoimmune hepatitis. Hum Immunol. 2001;62:1356-62.

31. Bittencourt PL, Palacios SA, Cancado EL, Porta G, Carrilho FJ, Laudanna AA, et al. Cytotoxic T lymphocyte antigen-4 gene polymorphisms do not confer susceptibility to autoimmune hepatitis types 1 and 2 in Brazil. Am J Gastroenterol. 2003;98: 1616-20.

32. Fan LY, Tu XQ, Cheng QB, Zhu Y, Feltens R, Pfeiffer T, et al. Cytotoxic $\mathrm{T}$ lymphocyte associated antigen-4 gene polymorphisms confer susceptibility to primary biliary cirrhosis and autoimmune hepatitis in Chinese population. World J Gastroenterol. 2004;10:3056-9.

33. Schott E, Witt H, Pascu M, van Boemmel F, Weich V, Bergk A, et al. Association of CTLA4 single nucleotide polymorphisms with viral but not autoimmune liver disease. Eur J Gastroenterol Hepatol. 2007;19:947-51.

34. Umemura T, Ota M, Yoshizawa K, Katsuyama Y, Ichijo T, Tanaka E, et al. Association of cytotoxic T-lymphocyte antigen 4 gene polymorphisms with type 1 autoimmune hepatitis in Japanese. Hepatol Res. 2008;38:689-95.

35. van Gerven NM, de Boer YS, Zwiers A, van Hoek B, van Erpecum KJ, Beuers U, et al. Cytotoxic T lymphocyte antigen-4 $+49 \mathrm{~A} / \mathrm{G}$ polymorphism does not affect susceptibility to autoimmune hepatitis. Liver Int. 2013;33:1039-43.

36. Hiraide A, Imazeki F, Yokosuka O, Kanda T, Kojima H, Fukai K, et al. Fas polymorphisms influence susceptibility to autoimmune hepatitis. Am J Gastroenterol. 2005;100:1322-9.

37. Agarwal K, Czaja AJ, Donaldson PT. A functional Fas promoter polymorphism is associated with a severe phenotype in type 1 autoimmune hepatitis characterized by early development of cirrhosis. Tissue Antigens. 2007;69:227-35.

38. Pociot F, Briant L, Jongeneel CV, Molvig J, Worsaae H, Abbal $\mathrm{M}$, et al. Association of tumor necrosis factor (TNF) and class II major histocompatibility complex alleles with the secretion of
TNF-alpha and TNF-beta by human mononuclear cells: a possible link to insulin-dependent diabetes mellitus. Eur J Immunol. 1993;23:224-31.

39. Czaja AJ, Cookson S, Constantini PK, Clare M, Underhill JA, Donaldson PT. Cytokine polymorphisms associated with clinical features and treatment outcome in type 1 autoimmune hepatitis. Gastroenterology. 1999;117:645-52.

40. Cookson S, Constantini PK, Clare M, Underhill JA, Bernal W, Czaja AJ, et al. Frequency and nature of cytokine gene polymorphisms in type 1 autoimmune hepatitis. Hepatology. 1999;30:851-6.

41. Yokosawa S, Yoshizawa K, Ota M, Katsuyama Y, Kawa S, Ichijo $\mathrm{T}$, et al. A genomewide DNA microsatellite association study of Japanese patients with autoimmune hepatitis type 1. Hepatology. 2007;45:384-90.

42. Hirschfield GM, Liu X, Xu C, Lu Y, Xie G, Gu X, et al. Primary biliary cirrhosis associated with HLA, IL12A, and IL12RB2 variants. N Engl J Med. 2009;360:2544-55.

43. Hirschfield GM, Liu X, Han Y, Gorlov IP, Lu Y, Xu C, et al. Variants at IRF5-TNPO3, 17q12-21 and MMEL1 are associated with primary biliary cirrhosis. Nat Genet. 2010;42:655-7.

44. Liu X, Invernizzi P, Lu Y, Kosoy R, Bianchi I, Podda M, et al. Genome-wide meta-analyses identify three loci associated with primary biliary cirrhosis. Nat Genet. 2010;42:658-60.

45. Mells GF, Floyd JA, Morley KI, Cordell HJ, Franklin CS, Shin $\mathrm{SY}$, et al. Genome-wide association study identifies 12 new susceptibility loci for primary biliary cirrhosis. Nat Genet. 2011;43:329-32.

46. Karlsen TH, Franke A, Melum E, Kaser A, Hov JR, Balschun T, et al. Genome-wide association analysis in primary sclerosing cholangitis. Gastroenterology. 2010;138:1102-11.

47. Melum E, Franke A, Schramm C, Weismuller TJ, Gotthardt DN, Offner FA, et al. Genome-wide association analysis in primary sclerosing cholangitis identifies two non-HLA susceptibility loci. Nat Genet. 2011;43:17-9.

48. Liu JZ, Hov JR, Folseraas T, Ellinghaus E, Rushbrook SM, Doncheva NT, et al. Dense genotyping of immune-related disease regions identifies nine new risk loci for primary sclerosing cholangitis. Nat Genet. 2013;45:670-5.

49. de Boer YS, van Gerven NM, Zwiers A, Verwer BJ, van Hoek B, van Erpecum KJ, et al. Genome-wide association study identifies variants associated with autoimmune hepatitis type 1 . Gastroenterology. 2014;147(443-52):e5. 